\title{
Survey: the management of pregnant women with a history of excisional treatment of the uterine cervix for cervical intra-epithelial neoplasia
}

\author{
Faisal M. S. Basama • Periti Angala
}

Received: 19 March 2010 / Accepted: 8 August 2010 /Published online: 10 September 2010

(C) Springer-Verlag 2010

\begin{abstract}
The purpose of this study is to gauge the management of pregnant women with a past history of cervical excisional treatments for cervical intra-epithelial neoplasia (CIN). A postal survey of 120 consultant obstetricians and gynaecologists in the northwest of England was done. The response rate was $41.7 \%$. Thirty-seven respondents (74\%) agreed with the evidence that cervical excisional treatment increases the risk of late miscarriage, preterm labour, premature rupture of the membranes and spontaneous rupture of the membranes at term. Thirty-one (62\%) think that cervical assessment during pregnancy in women who had excisional treatments is not essential, nevertheless, $72 \%$ of the respondents utilise transvaginal ultrasonography alone or in combination with other methods to assess the cervix in these women. Seventeen (34\%) assess the cervix monthly and nineteen $(38 \%)$ carry out variable assessments ranging between once in the first trimester and every 6-8 weeks. Thirty-one (62\%) offer cervical cerclage and 28 (56\%) will offer it between 13-16 weeks gestation. Twenty-four (48\%) would offer preconception transabdominal cervical cerclage to at-risk women. Forty $(80 \%)$ do not believe that previous excisional treatment will alter the vaginal flora and only eight (16\%) perform high vaginal swabs. There is a lack of consensus and consistency in the cervical assessment for the prediction of the risk of preterm birth in women who had cervical excisional treatments for CIN. Transvaginal ultrasonography alone or in combination with other methods is the
\end{abstract}

F. M. S. Basama $(\bowtie)$

Department of Obstetrics and Gynaecology,

Royal Lancaster Infirmary,

Ashton Road, Lancaster LA1 4RP Lancashire, UK

e-mail: fbasama@hotmail.com

P. Angala

Royal Preston Hospital,

Sharoe Green Lane, Preston PR2 9HT, UK most favoured technique in cervical assessment. The majority of the respondents offer cervical cerclage. In the presence of evidence that cervical excisional treatment for CIN carries a real risk of pregnancy loss and morbidity, there is a need for an agreed and standardised strategy in cervical assessment and intervention techniques.

Keywords Cervical excisional treatments · Uterine cervix . Cervical intra-epithelial neoplasia - LLETZ · Cone biopsy · Late miscarriage · Preterm labour $\cdot$ Cervical cerclage

\section{Introduction}

Excisional treatments of the uterine cervix for cervical intra-epithelial neoplasia (CIN) such as cervical cone biopsy, cervical laser conisation (CLC) and loop electrosurgical excision procedure (LEEP) may increase the risk of preterm delivery, low birth weight and pre-labour preterm rupture of the membranes (PPROM) in subsequent pregnancies [1-7]. A met-analysis in 2006 [8] showed that all the cervical excisional procedures to treat $\mathrm{CIN}$ have similar pregnancy-related morbidities.

The depth and volume of the tissues excised correlate with the outcomes in subsequent pregnancies and a cone height of at least $10 \mathrm{~mm}$ has been recognised as an independent risk factor for the duration of pregnancy and for the occurrence of preterm delivery in subsequent pregnancy [9] and a relatively large LEEP significantly increases risk of low birth weight and preterm birth [10].

Excisional procedures to treat CIN such as large loop excision of the transformation zone (LLETZ), LEEP, CLC and cold knife cone in young women are increasing with no evident adverse effects on fertility [8]; consequently, the number of pregnant women who had these treatments is expected to rise. There is no consensus among obstetricians 
and gynaecologists as to how to manage these at-risk women when they become pregnant and it would seem beneficial to gauge the current practices in order to inform future management.

\section{Methods}

This is a postal survey (see Appendix 1) to 120 consultant obstetricians and gynaecologists working in the North West of England, UK. All but one respondent, a gynaecological oncologist, are practicing general obstetrics and gynaecology. The posted survey included a stamped-return envelope.

\section{Results}

All the results pertain to women with excisional treatment to the uterine cervix. The response rate is $41.7 \%(50 / 120)$. Thirty-seven respondents (74\%) agree with the evidence that cervical excisional treatment (LLETZ, Laser cone, cold knife cone and LEEP) to the cervix for CIN increases the risk of late miscarriage, preterm labour, premature rupture of the membranes (PROM) and spontaneous rupture of the membranes (SROM). One (2\%) did not answer and 12 (24\%) disagree. Eight out of $50(16 \%)$ will assess the cervix by ultrasonography, six out of $50(12 \%)$ would offer cervical cerclage to women with previous pregnancy loss, PROM or SROM, or with cervical length of less than $2 \mathrm{~cm}$ and six out of 50(12\%) would offer preconception transabdominal cervical cerclage to high-risk women who had excisional treatment, repeated treatments, second trimester loss, history of preterm labour or PROM.

Table 1 in Appendix 2 illustrates the respondents' views about cervical assessment during pregnancy. Twenty (40\%) did not comment on their current practices; among them are 16 of the $18(88.9 \%)$ who thought cervical assessment is essential. The practices of $29(58 \%)$ are illustrated in Table 2 and 3 in Appendix 2. Table 3 outlines the conditions for cervical assessment by 14 respondents.

Charts 1 and 2 in Appendix 3 illustrate the methods and frequency of cervical assessment, respectively. Twenty out of the $31(64.5 \%)$ who thought assessment is not essential do assess the cervix. Thirty-one respondents $(62 \%)$ offer cervical cerclage, 17 (34\%) do not and two (4\%) did not comment.

Tables 4 and 5 in Appendix 2 show the indications and timing of cervical cerclage, respectively. Twenty-four (48\%) would offer preconception transabdominal cervical cerclage to high-risk women, $23(46 \%)$ would not and three $(6 \%)$ did not comment. Seven $(14 \%)$ think that previous excisional treatment will alter the vaginal flora, $40(80 \%)$ disagree and three $(6 \%)$ did not comment. Eight $(16 \%)$ perform high vaginal swabs (HVS), see Table 6 in Appendix 2.

\section{Discussion}

The physiological and anatomical roles of the uterine cervix in the support and protection of intra-uterine pregnancy are fundamental. Any trauma to the cervix from cervical excisional procedures such as cervical cold knife cone biopsy, CLC, loop electrosurgical excision procedure (LEEP) and large loop excision of the transformation zone (LLETZ) has the potential of affecting the integrity of this vital organ. The standard excisional treatment of the cervix to treat CIN in our hospital and in other hospitals in the North West region of England is LLETZ and, occasionally, cold knife biopsy. A probable sequel of the removal of cervical connective tissue is shortening, scarring and loss of plasticity resulting in decreased tensile strength of the cervix, increased vulnerability of the membranes to shearing forces, loss of protection from cervical mucus-secreting glands and increased risk of ascending infection. All these factors will, theoretically, increase the woman's susceptibility to preterm labour, PPROM, PROM and SROM. A shorter time interval between treatment and conception may increase the risk of preterm birth [11]. On the other hand, CIN, regardless of treatment, could lead to increased preterm birth [12] and women with CIN are more likely to be cigarette smokers - a well documented association with preterm labour.

Twenty-six per cent of the respondents disagree with the evidence from retrospective observational data that cervical excisional procedures carry similar pregnancy-related morbidity [1-8]. This could be a reflection of the uncertainty induced by earlier studies, which were unclear about the effect of these treatments on pregnancy outcome and subsequent risk of preterm delivery [13-16] or could be reservations regarding the design of some of the earlier studies [6]. Thirty-six per cent of the respondents would routinely perform cervical assessment on women with excisional treatment of cervix, and 14 respondents outlined the conditions to perform the assessment (Table 3). Arguably, if this is to be the standard practice then there could be financial implications to the NHS, but this should be balanced against the financial burden of preterm labour.

The response rate to the survey is low (41.7\%) compared to an average response rate of $57.5 \%$ among doctors [17]. It could be argued that the response rate could have been better if reminder questionnaires were sent to non-respondents. The researchers admit that the survey may not be representative and is likely biased and it could be that those who responded were the only ones who believe that active intervention during pregnancy after cervical excisional treatment is necessary. This limited survey has highlighted the lack of consensus on the need of standardised strategies in cervical assessment for the prediction of preterm birth in susceptible women. Nearly two thirds of the respondents do not believe that cervical assessment is required during pregnancy and 
$40 \%$ did not comment on their current practices. The survey also showed variations in practices. Digital, direct visual and transvaginal ultrasonographic assessments were all employed in the assessment of the cervix. The ideal and objective cervical screening test should be reproducible, acceptable, affordable, highly sensitive and specific. Digital and direct visual assessment of cervical length are crude and subjective and do not meet these standards in contrast to transvaginal ultrasonography, which is less subjective, and in addition, there is an accumulating experience with this technique. Apparently, the technique is popular among the respondents as $72 \%$ of them utilise it alone or in combination with other methods including $64.5 \%$ of those who thought cervical assessment is not essential.

The prevention of preterm delivery rests on the recognition of the predisposing factors and the diagnosis of a preclinical stage. Transvaginal ultrasonography of the cervix may have a role in the prediction of the risk of early preterm delivery in both high- and low-risk women and deserves further rigorous testing to prove its value in clinical practice. A study in 2006 [18] showed that transvaginal ultrasonography in high-risk women could, independently, demonstrate shorter cervical lengths than in low-risk controls and similar lengths to women with previous spontaneous preterm birth and could predict preterm birth in women who have had LEEP. A cervical length of $<3.0 \mathrm{~cm}$, further cervical shortening or opening of the cervix with uterine fundal pressure have all been suggested as predictive of preterm delivery or cervical incompetence requiring cerclage $[19,20]$. A shortened cervical length in the mid-trimester may preferentially predict early, as opposed to later, spontaneous preterm birth in highrisk women [21]. Paradoxically, funnelling, as an independent finding, may not add appreciably to the risk of early gestational age at delivery associated with a shortened cervical length $[19,22]$. A population-based prospective multi-centre study [23] provides a model that can give an accurate patientspecific risk of preterm delivery. It showed that the detection rate of screening by a combination of maternal factors and the measurement of cervical length was substantially higher than that of screening by each method alone.

There is no agreement among the respondents to the frequency and timing of cervical assessment. One third (34\%) assess the cervix monthly and the practices of the rest is either not known (28\%) or widely variable (38\%) between a single assessment in the first trimester to assessment every 68 weeks. The timing of the cervical assessment is crucial, and common sense would indicate that this should start early in the second trimester when most of pregnancy losses due to foetal abnormalities would have occurred.

Cervical cerclage might be associated with reduced preterm labour and improved perinatal outcome in women with cervical changes detected by ultrasonography [24] and in certain highrisk group of women with recurrent late miscarriages [25]; however, other interventions might be contributory to the improved outcomes [26]. Early cervical cerclage does not appear to offer significant benefit over early transvaginal ultrasonography in women with unclear history of incompetent cervix [27]. There is uncertainty about the role of cervical cerclage for women who have a short cervix on ultrasound $[24,28,29]$; nonetheless, $62 \%$ of the respondents would offer cervical cerclage to women with previous pregnancy loss, PROM, SROM or cervical length of less than $2 \mathrm{~cm}$. It is noteworthy that some of those who disagree with the evidence still assess the cervix by ultrasonography and would offer cervical or transabdominal cervical cerclage. More than half $(56 \%)$ of the respondents would offer cervical cerclage between 13 and 16 weeks gestation and $16 \%$ extend the offer to 26 weeks. The end of the second trimester heralds the end of the natural foetal wastage; hence, choosing 13 weeks as the earliest time for the insertion of transvaginal cerclage is logical while the selection of 26 weeks as the latest cutoff time is probably influenced by advances in neonatal medicine and better neonatal survival rates achieved by many units in infants delivered at or beyond 26 weeks gestation. Although transabdominal cervical cerclage carries potentially higher morbidity [30], it may offer improved neonatal survival with lesser morbidity in carefully selected women [31-35] and performing the procedure preconceptionally might be a safer alternative [36]. Almost half of the respondents (48\%) agree with this assumption and would offer it to women who had excisional treatment, repeated treatments, second trimester loss, preterm labour or PROM, and this could be an overrepresentation of those who would actively intervene.

The effect of cervical excisional treatments on the vaginal flora is uncertain and a Cochrane systematic review of five randomised controlled trials [37] has shown that there is no benefit in screening and treating all pregnant women for bacterial vaginosis in order to prevent preterm birth and its consequences; nonetheless, $20 \%$ of the respondents believe that previous excisional treatment will alter the vaginal flora.

\section{Conclusion}

The result of this limited survey does not claim accuracy in determining the opinion among practitioners and may have a tendency to bias; hence, it should be viewed with caution. Despite the majority of the respondents agreeing with the evidence that cervical excisional treatments poses obstetrical risk, there is a lack of consensus and consistency in the need and timing of cervical assessment for the prediction of the risk of preterm birth in susceptible women. Many respondents have failed to mention their current practices, and transvaginal ultrasonography alone or in combination with other methods is the most favoured technique used in cervical assessment. The presence of evidence that cervical excisional treatment for CIN 
carries a real risk of pregnancy loss and morbidity warrants the need for an agreed and standardised strategy in cervical assessment and in intervention techniques. A more comprehensive national survey is required.

Acknowledgement We would like to thank all the respondents who spared part of their valuable time to fill this questionnaire.

Declaration of interest The authors report no conflicts of interest. The authors alone are responsible for the content and writing of the paper.

\section{Appendix 1}

Questionnaire for the management practices in pregnant women with excisional treatment (LLETZ, Laser cone, cold knife cone \& LEEP) to cervix

There is evidence from research and literature review that women with previous excisional treatment to cervix has an increased the risk of late miscarriage, preterm labour, PROM, SROM $(1,2,3,4,5)$. Please notice that some questions might require more than one answer.

1) Q. Do you agree?

$$
\text { Yes } \square \quad \text { No } \square
$$

2) Q. Do you think that cervical assessment is essential in current pregnancy in women with previous history of excisional treatment to cervix?

Yes $\square \quad$ No $\square$

If yes go to question no 4

If No go to question no 3

3) Q. What is your current practice?

(2)

4) Q. How do you assess cervical length?

- Digital

- TVS

- Speculum

$\square$

- None of the above

$\square$

5) Q If yes how often it is required?

- Monthly

- Each trimester

$\square$

- Other please specify

6) Q. Do offer cervical cerclage?

$$
\text { Yes } \square \quad \text { No } \square
$$

7) Q. If yes in which group of patients cervical cerclage is needed?

- All women who had excisional treatment to cervix

- Women with two or more previous cervical excisional treatment

- Evidence of previous pregnant loss, preterm labour, PROM

- Women with cervical length less than $2 \mathrm{~cm}$

8) Q. At what gestation you think cervical cerclage should be offered?

9) Q. Do you think trans-abdominal cervical cerclage should be offered preconceptionally to women who had excisional treatment and had repeated treatments, second trimester loss, preterm labour, PROM?

$$
\text { Yes } \square \quad \text { No } \square
$$

10) Q. Do you believe that previous excisional treatment will alter vaginal flora?

$$
\text { Yes } \square \quad \text { No } \square
$$

11) Q. If yes, do you do HVS?

$$
\text { Yes } \square \quad \text { No } \square
$$

12) Q. If yes then at what gestation do you do HVS?

13) Q. Any additional information you would like to add in the management of these women:

$\overline{-}+\overline{ }$

Thanks for your valuable time in filling this questionnaire
Appendix 2

Table 1 Illustration of the respondents' views about cervical

\begin{tabular}{|c|c|}
\hline $6(12)$ & Treat women as low risk \\
\hline $3(6)$ & Guided by the volume and type of treatment \\
\hline $1(2)$ & $\begin{array}{l}\text { Assess in mid and late second trimester } \\
\text { and in early third trimester }\end{array}$ \\
\hline $1(2)$ & $\begin{array}{l}\text { Assess and counsels prior to treatment and } \\
\text { during pregnancy }\end{array}$ \\
\hline $1(2)$ & $\begin{array}{l}\text { No assessment if asymptomatic with normal } \\
\text { colposcopy and smear }\end{array}$ \\
\hline $1(2)$ & $\begin{array}{l}\text { Refer to the risk clinic if had a cone biopsy } \\
\text { or repeated LLETZ }\end{array}$ \\
\hline $1(2)$ & $\begin{array}{l}\text { Document the treatment to increase staff } \\
\text { awareness }\end{array}$ \\
\hline $1(2)$ & Administer steroids \\
\hline $14(28)$ & Assess the cervix only in certain conditions \\
\hline
\end{tabular}
assessment during pregnancy

\begin{tabular}{ll}
\hline Number of respondents (\%) & Views \\
\hline $18(36)$ & $\begin{array}{c}\text { Cervical assessment during pregnancy } \\
\text { is essential } \\
31(62)\end{array}$ \\
$\begin{array}{l}\text { Cervical assessment during pregnancy } \\
\text { is not essential }\end{array}$ \\
No answer
\end{tabular}

Table 2 Illustration of the practices of $29(58 \%)$ of the respondents

Number of $\quad$ Practices
respondents $(\%)$

Table 3 Outline of the conditions for cervical assessment by 14 respondents

\begin{tabular}{ll}
\hline The conditions & $\begin{array}{l}\text { Number of } \\
\text { respondents }\end{array}$
\end{tabular}

Previous cone biopsy 5

Repeated treatment or two or more cone biopsy 4

Previous late miscarriage 1

Cone biopsy and multiple pregnancy 1

Cone biopsy and with evidence of cervical 1

shortening

Problems with previous pregnancy and 1

evidence of cervical shortening

The clinician is concerned 1

Total number 14 
Table 4 shows the respondents' opinions regarding the indications for cervical cerclage

The indications for cervical cerclage

Number of respondents $(\%)$

Previous pregnancy loss, PROM or SROM

$12(24)$

Cervical length is less than $2 \mathrm{~cm}$

$13(26)$

Previous pregnancy loss, PROM or SROM and

$10(20)$

women with cervical length less than $2 \mathrm{~cm}$

Two or more previous cervical excisional

treatments, previous pregnancy loss, PROM

or SROM and women with cervical length

less than $2 \mathrm{~cm}$

Two or more previous cervical excisional

treatments and women with evidence of

previous pregnancy loss, PROM or SROM

No comment

\section{Appendix 3}

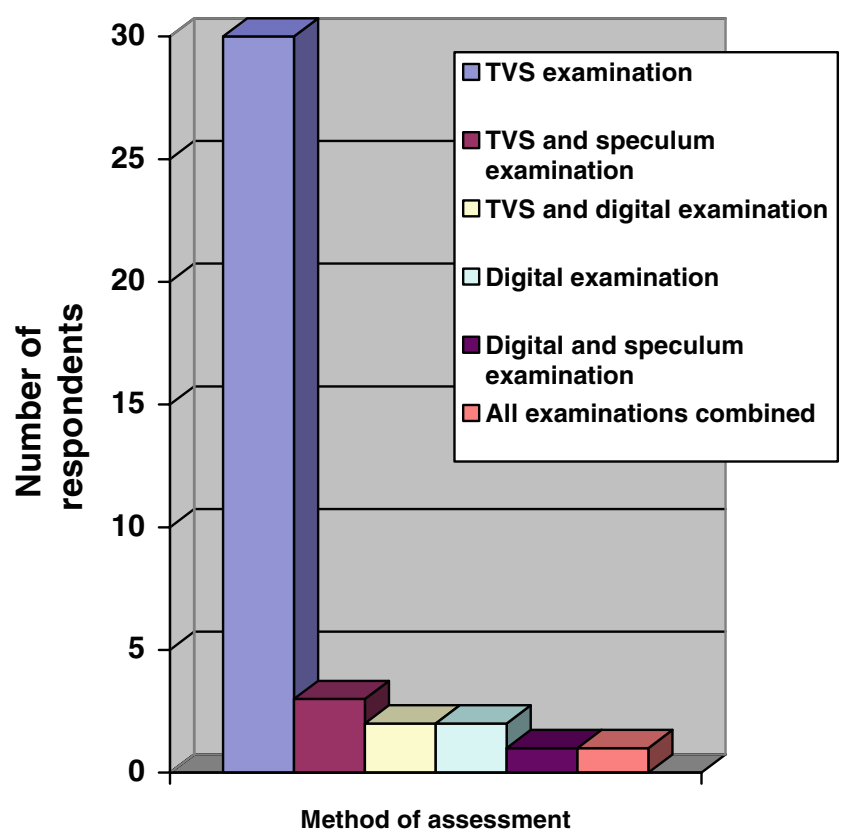

TVS: Trans Vaginal Sonography

Chart 1 Methods of cervical assessment

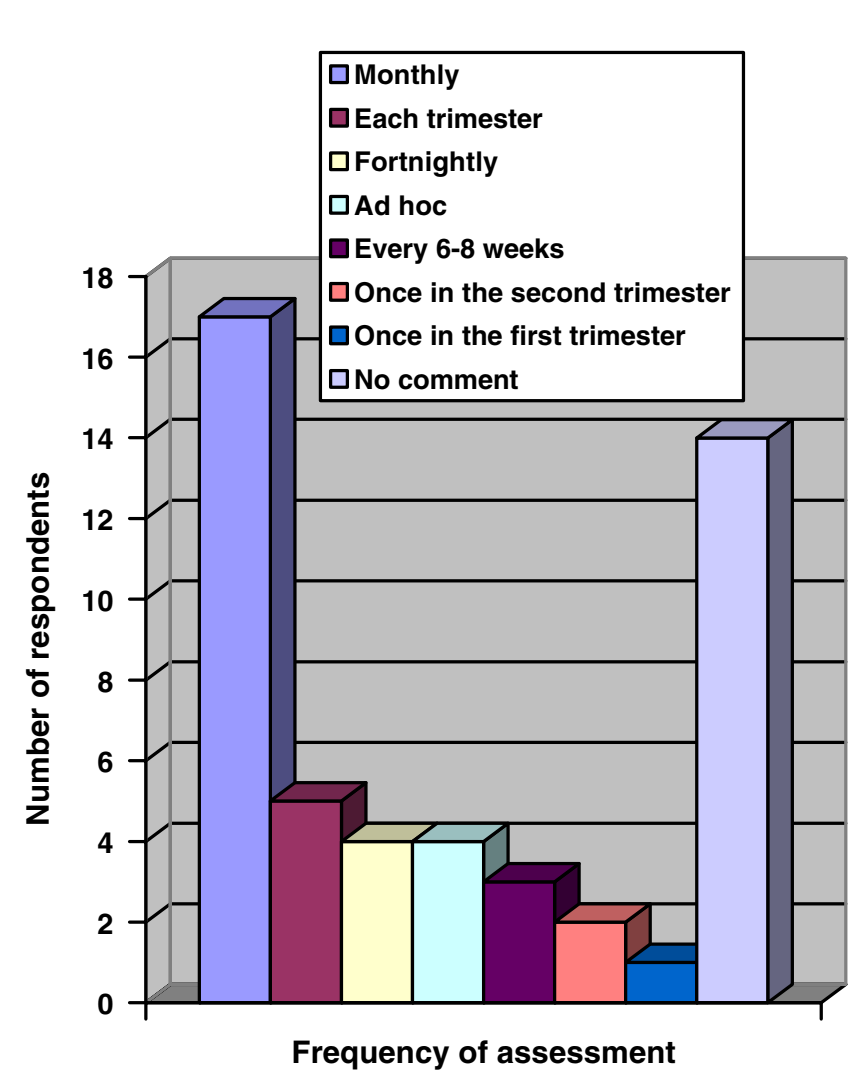

Chart 2 Frequency of cervical assessment
Table 6 Illustration of the timing of high vaginal swab

\begin{tabular}{ll}
\hline Time of HVS & Number of respondents \\
\hline At booking & 2 \\
Monthly & 3 \\
Each trimester & 1 \\
16 and 28 weeks & 1 \\
No comment & 2 \\
\hline
\end{tabular}

Table 5 Illustration of the timing of cervical cerclage insertion

\begin{tabular}{ll}
\hline $\begin{array}{l}\text { Number of } \\
\text { respondents }(\%)\end{array}$ & Time of cerclage \\
\hline $28(56)$ & $13-16$ weeks gestation \\
$8(16)$ & Up to 26 weeks \\
$2(4)$ & With evidence of funnelling or shortening \\
$12(24)$ & No comment \\
\hline
\end{tabular}




\section{References}

1. Jakobsson M, Gissler M, Sainio S, Paavonen J, Tapper AM (2007) Preterm delivery after surgical treatment for cervical intraepithelial neoplasia. Obstet Gynecol 109(2 Pt 1):309-313

2. Klaritsch P, Reich O, Giuliani A, Tamussino K, Haas J, Wninter R (2006) Delivery outcome after cold-knife conisation of the uterine cervix. Gynecol Oncol 103(2):604-607

3. Sjøborg KD, Vistad I, Myhr SS, Svenningsen R, Herzog C, Kloster-Jensen A, Nygărd G, Hole S, Tanbo T (2007) Pregnancy outcome after cervical cone excision: a case-control study. Acta Obstet Gynecol Scand 86(4):423-428

4. Nøhr B, Tabor A, Kjaer SK (2007) Loop electrosurgical excision of the cervix and the subsequent risk of preterm delivery. Acta Obstet Gynecol Scand 86(5):596-603

5. Crane JM (2003) Pregnancy outcome after loop electrosurgical excision procedure: a systematic review. Obstet Gynecol 102(5 Pt 1):1058-1062

6. Sadler L, Saftlas A, Wang W, Exeter M, Whittaker J, McCowan L (2004) Treatment for cervical intraepithelial neoplasia and risk of preterm delivery. JAMA 291(17):2100-2106

7. Samson SL, Bentley JR, Fahey TJ, Mckay DJ, Gill GH (2005) The effect of loop electrosurgical excision procedure on future pregnancy outcome. Obstet Gynecol 105(2):325-332

8. Kyrgiou M, Koliopoulos G, Martin-Hirsch P, Arbyn M, Prendiville W, Paraskevaidis E (2006) Obstetric outcomes after conservative treatment for intraepithelial or early invasive cervical lesions: systematic review and meta-analysis. Lancet 367(9509):489-498

9. Raio L, Ghezzi F, Di Naro E, Lüscher KP (1997) Duration of pregnancy after carbon dioxide laser conisation of the cervix: influence of cone height. Obstet Gynecol 90(6):978-982

10. Acharya G, Kjeldberg I, Hansen SM, Sørheim N, Jacobsen BK, Maltau JM (2005) Pregnancy outcome after loop electrosurgical excision procedure for the management of cervical intraepithelial neoplasia. Arch Gynecol Obstet 272(2):109-112

11. Himes KP, Simhan HN (2007) Time from cervical conisation to pregnancy and preterm birth. Obstet Gynecol 109(2 Pt 1):314319

12. Bruinsma F, Lumley J, Tan J, Quinn M (2007) Precancerous changes in the cervix and risk of subsequent preterm birth. Br J Obstet Gynaecol 114(1):70-80

13. Kristensen J, Kristenen FB (1993) Increased risk of preterm birth in women with cervical conisation. Obstet Gynecol 81(6):10051008

14. Paraskevaidis E, Koliopoulos G, Lolis E, Papanikou E, Agnantis NJ (2002) Delivery outcomes following loop electrosurgical excision procedure for microinvasive (FIGO stage IA1) cervical cancer. Gynecol Oncol 86(1):10-13

15. Tan L, Pepra E, Haloob RK (2004) The outcome of pregnancy after large loop excision of the transformation zone of the cervix. Obstet Gynecol 24(1):25-27

16. Van Rooijen M, Persson E (1999) Pregnancy outcome after laser vaporization of the cervix. Acta Obstet Gynecol Scand 78(4):346348

17. Cook JV, Dickinson HO, Eccles MP (2009) Response rates in postal surveys of healthcare professionals between 1996 and 2005: an observational study. BMC Health Serv Res 9(1):160

18. Crane JM, Delaney T, Hutchens D (2006) Transvaginal ultrasonography in the prediction of preterm birth after treatment for cervical intraepithelial neoplasia. Obstet Gynecol 107(1):37-44

19. To MS, Skentou C, Liao AW, Cacho A, Nicolaides KH (2001) Cervical length and funnelling at 23 weeks of gestation in the prediction of spontaneous early preterm delivery. Ultrasound Obstet Gynecol 18(3):200-203
20. Macdonald R, Smith P, Vyas S (2001) Cervical incompetence: the use of transvaginal sonography to provide an objective diagnosis. Ultrasound Obstet Gynecol 18(3):211-216

21. Owen J, Yost N, Berghella V, MacPherson C, Swain M, Dildy GA 3rd, Miodovnik M, Langer O, Sibai B (2004) Can shortened midtrimester cervical length predict very early spontaneous preterm birth? Am J Obstet Gynecol 191(1):298-303

22. Berghella V, Owen J, MacPherson C, Yost N, Swain M, Dildy GA 3rd, Miodovnik M, Langer O, Sibai B (2007) Natural history of cervical funnelling in women at high risk for spontaneous preterm birth. Obstet Gynecol 109(4):863-869

23. To MS, Skentou CA, Royston P, Yu CK, Nicolaides KH (2006) Prediction of patient-specific risk of early preterm delivery using maternal history and sonographic measurement of cervical length: a population-based prospective study. Ultrasound Obstet Gynecol 27(4):362-367

24. Althuisius SM, Dekker GA, Hummel P, Bekedam DJ, Van Geijn HP (2001) Final results of the Cervical Incompetence Prevention Randomized Cerclage Trial (CIPRACT): therapeutic cerclage with bed rest versus bed rest alone. Am J Obstet Gynecol 185(5):11061112

25. MRC/RCOG Working Party on Cervical Cerclage (1993) Final report of the Medical Research Council/Royal College of Obstetricians and Gynaecologists multicentre randomised trial of cervical cerclage. Br J Obstet Gynaecol 100:516-523

26. Novy MJ, Gupta A, Wothe DD, Gupta S, Kennedy KA, Gravett MG (2001) Cervical cerclage in the second trimester of pregnancy: a historical cohort study. Am J Obstet Gynecol 184 (7):1447-1454

27. Kelly S, Pollock M, Maas B, Lefebvre C, Manley J, Sciscione A (2001) Early transvaginal ultrasonography versus early cerclage in women with an unclear history of incompetent cervix. Am J Obstet Gynecol 184(6):1097-1099

28. Drakeley AJ, Roberts D, Alfirevic Z (2009) Cervical stitch (cerclage) for preventing pregnancy loss in women. Cochrane Database of Syst Rev 2003, (1):CD003253. doi:10.1002/ 14651858.CD003253

29. Rust OA, Atlas RO, Jones KJ, Benham BN, Balducci J (2000) A randomized trial of cerclage versus no cerclage among patients with ultrasonographically detected second-trimester preterm dilatation of the internal os. Am J Obstet Gynecol 183:830-835

30. Zaveri V, Aghajafari F, Amankwah K, Hannah M (2002) Abdominal versus vaginal cerclage after a failed transvaginal cerclage: a systematic review. Am J Obstet Gynecol 187(4):868-872

31. Cammarano CL, Herron MA, Parer JT (1995) Validity of indications for transabdominal cervicoisthmic cerclage for cervical incompetence. Am J Obstet Gynecol 172(6):1871-1875

32. Craig S, Fliegner JR (1997) Treatment of cervical incompetence by transabdominal cervicoisthmic cerclage. Aust N Z J Obstet Gynaecol 37(4):407-411

33. Gibb DM, Salaria DA (1995) Transabdominal cervicoisthmic cerclage in the management of recurrent second trimester miscarriage and preterm delivery. $\mathrm{Br} \mathrm{J}$ Obstet Gynaecol 102 (10):802-806

34. Lotgering FK, Gaugler-Senden IP, Lotgering SF, Wallenburg HC (2006) Outcome after transabdominal cervicoisthmic cerclage. Obstet Gynecol 107(4):779-784

35. Witt MU, Joy SD, Clark J, Herring A, Bowes WA, Thorp JM (2009) Cervicoisthmic cerclage: transabdominal vs. transvaginal approach. Am J Obstet Gynecol 201(1):105

36. Groom KM, Jones BA, Edmonds DK, Bennett PR (2004) Preconception transabdominal cervicoisthmic cerclage. Am J Obstet Gynecol 191(1):230-234

37. Brocklehurst $P$, Hannah M, McDonald $H$ (2000) Interventions for treating bacterial vaginosis in pregnancy. Cochrane Database of Syst Rev (2):CD000262 